AGH DRILLING, OIL, GAS • Vol. 35 • No. $1 \cdot 2018$

http://dx.doi.org/10.7494/drill.2018.35.1.181

\author{
Jan Macuda*, Kinga Klima**
}

\title{
SELECTION OF EFFECTIVE CHEMICAL COMPOUNDS FOR DRILLED WELLS****
}

\section{INTRODUCTION}

Drilled wells are subject to many complex physico-chemical processes that affect discharge capacity of filter and permeability of backfill, as well as rocks from the nappe in the filter-adjacent zone. This process is generally referred to as "aging" wells and is expressed by a decrease in performance unit $\mathrm{Q} / \mathrm{s}$ or an increase in depression unit s/Q. In case of quaternary and tertiary water intake, the process of filter and filter-adjacent zone colmatation is usually caused by precipitation of insoluble chemical compounds from the flowing water and settling of fine sand and clay fractions. The main components of such colmatation sediments are compounds of iron and carbonates. Iron oxides $\left(\mathrm{Fe}_{2} \mathrm{O}_{3}, \mathrm{FeO}\right)$ and iron hydroxides are the most common among ferrous compounds, and among carbonates the largest mass of colmatation sediments are calcium carbonates, magnesium carbonates and iron carbonates [1,2].

The course of colmatation process of quaternary and tertiary water intake wells can be significantly reduced by frequent renovation of wells by chemical methods. These treatments are aimed to restore proper technical conditions of wells operation as a result of removing colmatation sediments from the filter and filter-adjacent zone, as well as slowing down further process of their settling. Properly performed chemical renovation of wells does not endanger the environment, and significantly increase the efficiency of wells. This enables to cover the water demand to a greater extent and reduces the financial expenses compared to construction cost of a new well.

\footnotetext{
* AGH University of Science and Technology, Faculty of Drilling, Oil and Gas, Krakow, Poland

** AGH University of Science and Technology, The Faculty of Energy and Fuels, Krakow, Poland

*** Work performed within statutory research of Faculty of Drilling, Oil and Gas AGH UST no. 11.11.190.555
} 
Analysis of literature [1-4] shows that chemical methods in other countries constitute $40-60 \%$ of all renovation treatments. In Poland, such treatments constitute only $20-30 \%$ compared to other methods. Restrictions on application of this method in Poland result mainly from high costs related to the need of having specialized equipment for transporting and storing chemical agents, utilization of post-reaction liquid and specialized equipment for application of these agents in wells. Development of a universal and effective method would allow for optimization of the well renovation process without any additional procedures related to the removal of deposits from the filter column and minimization of negative impact on the natural environment.

Chemical methods, initially based on hydrochloric acid, had an acceptable efficiency only in $\mathrm{pH}$ range of $0.9-1.0$, which significantly increased the time of shutting down wells and caused problems with maintaining an appropriate technological regime. Currently, organic compounds and mixtures are commonly used for wells renovation, due to the higher $\mathrm{pH}$ of 2.7-3.0 and increased safety of their use [4].

Sodium dithionite and sodium pyrosulphite compounds (Fig. 1) due to their properties have been selected for laboratory tests related to dissolution of colmatation sediments in wells of quaternary water intake (Fig. 1). Commonly used acidic dithionate, due to its reduction properties and low toxicity level, has been used in e.g. environmental analytics for determination of bound and free ions in soil samples. In case of pyrosulphite, it is necessary to mention about its application as a disinfectant, corrosion inhibitor in water treatment process $[5,6]$.

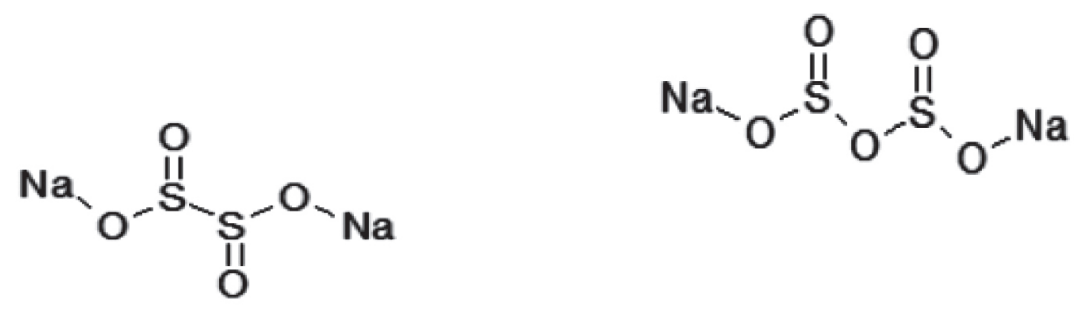

Fig. 1. Structural formula (from left) of sodium dithionite and sodium pyrosulphite

\section{METHODS AND MATERIALS}

Laboratory tests were based on a representative sample of well sediment taken from the filter column. The research problem was based on an attempt to identify a group of compounds that incrust on the filter and reduce its active surface area. The hypothesis was based on poorly soluble compounds containing in their structure irons and manganese $[7,8]$. The material signed as A1 constituted settlement with presumably complex matrix. The organoleptic evaluation allowed for their initial characterization. Rust, soft, loose in structure, slightly compact, uniform sediments. The apparently homogeneous 
material contained traces of detritus. After quantitative analysis, sample A1 was characterized by a relatively high content of manganese and iron.

Sediment dissolution attempts consisted in the direct treatment of 20 g sediment placed on filter paper of an average thickness with $200 \mathrm{ml}$ sodium pyrosulphite and sodium dithionite solution of $0.1 \mathrm{~mol} / \mathrm{dm}^{3}$. Next 24-hour exposure to the chemical agent, and finally rinsed several times with distilled water to obtain a constant $\mathrm{pH}$ of the filtrate and re-analysis of EDS sediment residue. The confrontation based on a change in percentage of the analyzed ions and organoleptic evaluation of the conciseness, color, texture and residue masses. These parameters were the basis for evaluation of the effectiveness of studied chemical compounds for each case and sample.

\section{DIFFRACTOMETRIC ANALYSIS OF SEDIMENT}

X-ray diffractometry allowed for a preliminary evaluation of studied material in terms of appearing phases. This study allows for quantitative and qualitative phase analysis and identification of crystalline phases. According to presented diffractogram (Fig. 2) the sample showed an amorphous character. However, a clear peak was observed, indicating the presence of $\mathrm{SiO}_{2}$ in the studied area of crystalline silica. In terms of matrix phase analysis, it can be assumed that sediment dissolution processes will be carried out using less aggressive reagents.

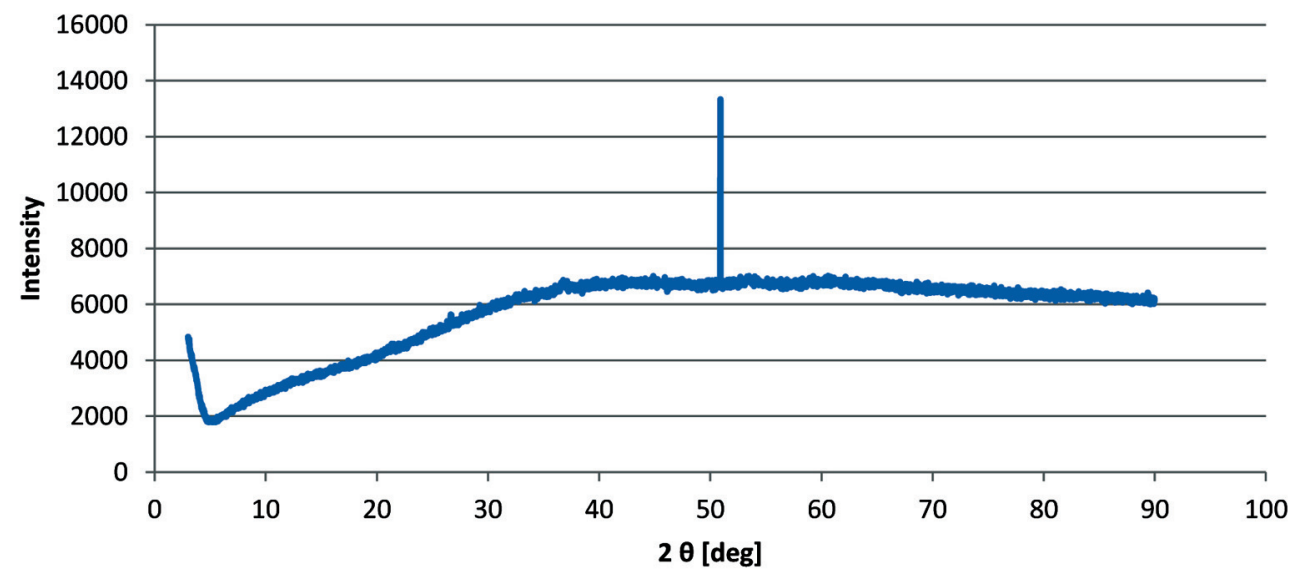

Fig. 2. Difractogram of sample A1

\section{QUANTITATIVE AND QUALITY ANALYSIS OF A1 SAMPLES}

Microanalysis of the sediment surface of sample A1 allowed for elementary identification of the matrix. Table 1 shows only the percentage of three main components of the 
colmatation sediment due to trace amount or negligible impact of other elements on the chemical collation process of the well filter: iron, manganese, calcium, carbon (organic material and calcium carbonate).

\section{Table 1}

Percentage of individual ions by reference to the total element content in relation to the total element content of all elements present in the material

\begin{tabular}{|c|c|c|}
\hline \multicolumn{3}{|c|}{$\begin{array}{c}\text { Elementary analysis sample A1 relative } \\
\text { to all elements present in the material }(100 \%)\end{array}$} \\
\cline { 2 - 3 } & $\mathrm{wt} \%$ & at $\%$ \\
\hline $\mathrm{Fe}$ & 31.69 & 12.82 \\
\hline $\mathrm{Mn}$ & 5.69 & 2.34 \\
\hline $\mathrm{Ca}$ & 5.03 & 2.84 \\
\hline $\mathrm{C}$ & 10.13 & 19.05 \\
\hline Others & 47.46 & 62.95 \\
\hline
\end{tabular}

\section{RESULTS}

Analysis of results in Table 2 shows that sodium dithionate is a more effective chemical compound in quantitative terms for three main sedimentary elements.

Table 2

Summary observation of post-reaction samples of colmatation sediment A1

\begin{tabular}{|l|c|c|}
\hline \multicolumn{3}{|c|}{ Post-reaction sample A1 $m_{o}=20 \mathrm{~g}$} \\
\hline & A1-P & A1-D \\
\hline \multicolumn{3}{|c|}{ Percentage of the element } \\
\hline Iron [Fe] & 30.72 & 31.03 \\
\hline Manganese [Mn] & 0.3 & 5.01 \\
\hline Calcium [Ca] & 0.25 & 2.39 \\
\hline & Observations when reagent is added \\
\hline Quantity of sediment [g] & 14.1 & 12.9 \\
\hline Color & Dark-brown & Dark-brown \\
\hline Conciseness & Light & Light \\
\hline
\end{tabular}


The figures are weight percentage of comprehensive elementary analysis, which is the basis for a quantitative assessment. In addition, a positive effect on physical properties of sediment was observed, as well as a $35 \%$ reduction of sediment mass in relation to the initial weight. The post-reaction sediment with dithionate showed a lower conciseness and relatively darker color, and was easily removed by a stream of distilled water from the filter paper.

\section{CONCLUSIONS}

The efficiency of sodium dithionite in the dissolving process of colmatation sediments is supported not only by the lowest recorded content of manganese and iron in post-reaction samples, in confrontation with the results obtained for sodium pyrosulphite, but also by visible changes in the appearance of sediments. Although obtained results do not indicate a drastic decrease in the content of these elements, the sediment has become significantly light by observing the surface of medium thick filter disc, and the color has a distinctly dark-brown shade. It can be assumed that there has been a change in the degree of oxidizing elements, including irons and manganese, which may also result in transformation of complex compounds poorly soluble into compounds with other physico and chemical properties. Comparing results obtained for samples with sodium pyrosulphite and dithionite solution, we can observe similarity both for quantitative changes $(\sim 35 \%$ reduction in sediment mass) and for a clear transformation in the dimension of character and appearance of studied material. Due to observed tendency to change the physical character of sediment and to reduce the content of individual compounds contributing to intensification of the chemical colmatation process of wells, both components can be considered as potential substrates of the mixture, which can effectively inhibit this process and contribute to increase the efficiency of chemical methods of well renovation.

\section{REFERENCES}

[1] Driscoll F.G.: Groundwater and Wells. Johnson Division, 1986.

[2] Nielsen D.M.: Ground-Water Monitoring. Lewis Publishers, Boca Raton, USA, 1991.

[3] Houben G., Treskatis C.: Water Well Rehabilitation and Reconstruction. McGraw Hill, New York, USA, 2007.

[4] Houben G., Weihe U.: Spatial Distribution of Incrustations around a Water Well after 38 Years of Use. Groundwater, vol. 48, iss. 1, 2010, pp. 53-58. 
[5] Biber M.V., dos Santos Afonso M., Stumm W.: The coordination chemistry of weathering: IV. Inhibition of the dissolution of oxide minerals. Geochimica et Cosmochimica Acta, 58, 1994, pp. 1999-2010.

[6] Lyons D., Nickless G.: Inorganic Sulfur Chemistry. Elsevier, Amsterdam 1968.

[7] Houben G.J.: Iron oxide incrustations in wells. Part 1: Genesis, mineralogy and geochemistry. Applied Geochemistry, 18, iss. 6, 2003, pp. 927-939.

[8] Houben G.J.: Iron oxide incrustations in wells. Part 2: Chemical dissolution and modeling. Applied Geochemistry, 18, iss. 6, 2003, pp. 941-954. 